\title{
Modelling the effects of decreasing the inter- competition coefficients on biodiversity loss
}

\author{
Ekaka-a, E. N. ${ }^{1}$; Eke, Nwagrabe ${ }^{2}$; Atsu, J. U. ${ }^{3}$
}

\begin{abstract}
${ }^{1}$ Department of Mathematics, Rivers State University Nkporlu-Oroworukwo, Port Harcourt, Rivers State
${ }^{2}$ Department of Mathematics/Statistics, Ignatius Ajuru University of Education, Port Harcourt, Rivers State

${ }^{3}$ Department of Mathematics/Statistics, Cross River University of Technology, Calabar, Nigeria.
\end{abstract}

\begin{abstract}
The notion of a biodiversity loss has been identified as a major devastating biological phenomenon which needs to be mitigated against. In the short term, we have utilised a Matlab numerical scheme to quantify the effects of decreasing and increasing the inter competition coefficients on biodiversity loss and biodiversity gain. On the simplifying assumption of a fixed initial condition $(4,10)$, two enhancing factors of intrinsic growth rates, two inhibiting growth rates of intra - competition coefficients and two inhibiting growth rates of inter-competition coefficients. The novel results that we have obtained; which we have not seen elsewhere complement our recent contribution to knowledge in the context of applying a numerical scheme to predict both biodiversity loss and biodiversity gain.
\end{abstract}

Keywords- Competition coefficients, biodiversity loss, biodiversity gain, numerical scheme, initial condition, intrinsic growth rate.

\section{INTRODUCTION}

Following the recent application of a numerical simulation to model biodiversity (Atsu and Ekaka-a 2017), we have come to observe that the mathematical technique of a numerical simulation which is rarely been applied to interpret the extent of biodiversity loss and biodiversity gain is an important short term and long term quantitative scientific process. We will expect the application of a numerical simulation to model biodiversity to contribute to other previous research outputs.

\section{MATERIALS AND METHODS}

The core method of ODE 45 numerical scheme has been coded to analyze a Lotka - Volterra mathematical structure dynamical system of non - linear first order differential equation with the following parameter values: The intrinsic growth rate of the first species is estimated to be 0.1 ; the intrinsic growth rate of the second yeast species is estimated to be 0.08 ; the intra - competition coefficients due to the self-interaction between the first yeast species and itself is estimated to be 0.0014; the intra - competition coefficients due to the self-interaction between the second yeast species and itself is estimated to be 0.001 ; the intra - competition coefficients which is another set of inhibiting factors are estimated to be 0.0012 and 0.0009 respectively. The aim of this present analysis is to vary the inter - competition coefficient together and quantify the effect of this variation on biodiversity loss and biodiversity gain in which the initial condition is specified by $(4,10)$ for a shorter length of growing season of twenty (20) days

\section{RESULTS}

The results of these numerical simulation analyses are presented in Table 1, Table 2, and Table 3

\section{DISCUSSION OF RESULTS}

The results are presented and discussed as follows.

Table.1: Evaluating the effect of $r_{1}=0.00012$ and $r_{2}=0.00009$ together on $x(t)$ andy $(t)$ using ODE 45 numerical scheme

\begin{tabular}{|c|c|c|c|c|c|c|}
\hline Example & $x(t)$ & $x_{m}(t)$ & $B L(\%)$ & $y(t)$ & $y_{m}(t)$ & $B L(\%)$ \\
\hline 1 & 4.0000 & 4.0000 & 0 & 10.0000 & 10.0000 & 0 \\
\hline 2 & 4.4497 & 4.4003 & 1.1113 & 10.7618 & 10.7253 & 0.3398 \\
\hline 3 & 4.9514 & 4.8381 & 2.2864 & 11.5776 & 11.4950 & 0.7130 \\
\hline 4 & 5.5111 & 5.3167 & 3.5262 & 12.4505 & 12.3107 & 1.1229 \\
\hline 5 & 6.1356 & 5.8391 & 4.8318 & 13.3844 & 13.1739 & 1.5728 \\
\hline 6 & 6.8325 & 6.4086 & 6.2034 & 14.3829 & 14.0857 & 2.0663 \\
\hline 7 & 7.6102 & 7.0287 & 7.6410 & 15.4502 & 15.0473 & 2.6074 \\
\hline 8 & 8.4778 & 7.7026 & 9.1439 & 16.5906 & 16.0597 & 3.2001 \\
\hline
\end{tabular}




\begin{tabular}{|c|c|c|c|c|c|c|}
\hline Example & $x(t)$ & $x_{m}(t)$ & $B L(\%)$ & $y(t)$ & $y_{m}(t)$ & $B L(\%)$ \\
\hline 9 & 9.4456 & 8.4339 & 10.7107 & 17.8090 & 17.1235 & 3.8490 \\
\hline 10 & 10.5247 & 9.2260 & 12.3396 & 19.1103 & 18.2391 & 4.5587 \\
\hline 11 & 11.7273 & 10.0822 & 14.0278 & 20.5002 & 19.4067 & 5.3340 \\
\hline 12 & 13.0666 & 11.0058 & 15.7718 & 21.9847 & 20.6261 & 6.1799 \\
\hline 13 & 14.5569 & 11.9997 & 17.5674 & 23.5705 & 21.8966 & 7.1015 \\
\hline 14 & 16.2134 & 13.0664 & 19.4097 & 25.2650 & 23.2175 & 8.1041 \\
\hline 15 & 18.0522 & 14.2084 & 21.2929 & 27.0765 & 24.5875 & 9.1927 \\
\hline 16 & 20.0902 & 15.4272 & 23.2106 & 29.0141 & 26.0047 & 10.3721 \\
\hline 17 & 22.3450 & 16.7240 & 25.1557 & 31.0880 & 27.4672 & 11.6469 \\
\hline 18 & 24.8344 & 18.0991 & 27.1208 & 33.3096 & 28.9723 & 13.0212 \\
\hline 19 & 27.5763 & 19.5521 & 29.0981 & 35.6920 & 30.5173 & 14.4981 \\
\hline 20 & 30.5884 & 21.0817 & 31.0794 & 38.2492 & 32.0987 & 16.0800 \\
\hline
\end{tabular}

Table.2: Evaluating the effect of $r_{1}=0.00018 a$ and $r_{2}=0.000135$ together on $x(t)$ andy $(t)$ using ODE 45 numerical

\begin{tabular}{|c|c|c|c|c|c|c|}
\hline Example & $x(t)$ & $x_{m}(t)$ & $B L(\%)$ & $y(t)$ & $y_{m}(t)$ & $B L(\%)$ \\
\hline 1 & 4.0000 & 4.0000 & 0 & 10.0000 & 10.0000 & 0 \\
\hline 2 & 4.4497 & 4.4030 & 1.0500 & 10.7618 & 10.7273 & 0.3210 \\
\hline 3 & 4.9514 & 4.8443 & 2.1611 & 11.5776 & 11.4995 & 0.6740 \\
\hline 4 & 5.5111 & 5.3273 & 3.3346 & 12.4505 & 12.3183 & 1.0619 \\
\hline 5 & 6.1356 & 5.8551 & 4.5715 & 13.3844 & 13.1852 & 1.4881 \\
\hline 6 & 6.8325 & 6.4313 & 5.8722 & 14.3829 & 14.1015 & 1.9561 \\
\hline 7 & 7.6102 & 7.0594 & 7.2370 & 15.4502 & 15.0686 & 2.4698 \\
\hline 8 & 8.4778 & 7.7432 & 8.6654 & 16.5906 & 16.0874 & 3.0332 \\
\hline 9 & 9.4456 & 8.4862 & 10.1565 & 17.8090 & 17.1588 & 3.6507 \\
\hline 10 & 10.5247 & 9.2924 & 11.7085 & 19.1103 & 18.2834 & 4.3269 \\
\hline 11 & 11.7273 & 10.1653 & 13.3193 & 20.5002 & 19.4616 & 5.0665 \\
\hline 12 & 13.0666 & 11.1085 & 14.9857 & 21.9847 & 20.6932 & 5.8748 \\
\hline 13 & 14.5569 & 12.1253 & 16.7041 & 23.5705 & 21.9779 & 6.7566 \\
\hline 14 & 16.2134 & 13.2188 & 18.4699 & 25.2650 & 23.3152 & 7.7174 \\
\hline 15 & 18.0522 & 14.3916 & 20.2780 & 27.0765 & 24.7040 & 8.7623 \\
\hline 16 & 20.0902 & 15.6458 & 22.1224 & 29.0141 & 26.1427 & 9.8963 \\
\hline 17 & 22.3450 & 16.9830 & 23.9966 & 31.0880 & 27.6297 & 11.1241 \\
\hline 18 & 24.8344 & 18.4039 & 25.8936 & 33.3096 & 29.1626 & 12.4501 \\
\hline 19 & 27.5763 & 19.9084 & 27.8060 & 35.6920 & 30.7388 & 13.8776 \\
\hline 20 & 30.5884 & 21.4956 & 29.7263 & 38.2492 & 32.3552 & 15.4095 \\
\hline & & & & & & \\
\hline
\end{tabular}

Table.3: Evaluating the effect of $r_{1}=0.001176$ and $r_{2}=0.000882$ together on $x(t)$ andy $(t)$ using ODE 45 numerical scheme

\begin{tabular}{|c|c|c|c|c|c|c|}
\hline Example & $x(t)$ & $x_{m}(t)$ & $B L(\%)$ & $y(t)$ & $y_{m}(t)$ & $B L(\%)$ \\
\hline 1 & 4.0000 & 4.0000 & 0 & 10.0000 & 10.0000 & 0 \\
\hline 2 & 4.4497 & 4.4486 & 0.0249 & 10.7618 & 10.7610 & 0.0076 \\
\hline 3 & 4.9514 & 4.9488 & 0.0516 & 11.5776 & 11.5757 & 0.0161 \\
\hline 4 & 5.5111 & 5.5066 & 0.0802 & 12.4505 & 12.4473 & 0.0255 \\
\hline 5 & 6.1356 & 6.1288 & 0.1108 & 13.3844 & 13.3795 & 0.0361 \\
\hline 6 & 6.8325 & 6.8227 & 0.1436 & 14.3829 & 14.3760 & 0.0479 \\
\hline 7 & 7.6102 & 7.5966 & 0.1787 & 15.4502 & 15.4407 & 0.0611 \\
\hline 8 & 8.4778 & 8.4595 & 0.2161 & 16.5906 & 16.5781 & 0.0759 \\
\hline 9 & 9.4456 & 9.4214 & 0.2560 & 17.8090 & 17.7925 & 0.0924 \\
\hline 10 & 10.5247 & 10.4933 & 0.2985 & 19.1103 & 19.0891 & 0.1109 \\
\hline
\end{tabular}




\begin{tabular}{|c|c|c|c|c|c|c|}
\hline Example & $x(t)$ & $x_{m}(t)$ & $B L(\%)$ & $y(t)$ & $y_{m}(t)$ & $B L(\%)$ \\
\hline 11 & 11.7273 & 11.6870 & 0.3437 & 20.5002 & 20.4732 & 0.1316 \\
\hline 12 & 13.0666 & 13.0155 & 0.3917 & 21.9847 & 21.9507 & 0.1549 \\
\hline 13 & 14.5569 & 14.4925 & 0.4425 & 23.5705 & 23.5279 & 0.1809 \\
\hline 14 & 16.2134 & 16.1329 & 0.4964 & 25.2650 & 25.2120 & 0.2101 \\
\hline 15 & 18.0522 & 17.9523 & 0.5532 & 27.0765 & 27.0108 & 0.2429 \\
\hline 16 & 20.0902 & 19.9670 & 0.6132 & 29.0141 & 28.9330 & 0.2795 \\
\hline 17 & 22.3450 & 22.1939 & 0.6763 & 31.0880 & 30.9883 & 0.3206 \\
\hline 18 & 24.8344 & 24.6499 & 0.7427 & 33.3096 & 33.1875 & 0.3666 \\
\hline 19 & 27.5763 & 27.3523 & 0.8123 & 35.6920 & 35.5428 & 0.4180 \\
\hline 20 & 30.5884 & 30.3176 & 0.8852 & 38.2492 & 38.0674 & 0.4753 \\
\hline
\end{tabular}

By using ODE 45 numerical scheme, we have observed that a ten (10) percent variation of the inter-competition coefficient has predicted a monotonically increasing values for the populations ranging from 4.000 to 30.5884 approximately when all the model parameters are fixed. For the same population, due to a variation of the intrinsic growth rates, we have obtained a new population of the first yeast species called $x_{1}(t)$ ranging from 4.000 to 21.0817. A biodiversity loss has occurred ranging from 0 and increasing monotonically to 31.0794 , quantified in percentage terms. In essence, example twenty (20) shows that the first yeast population during a shorter growing season of twenty (20) units of time is more vulnerable to the ecological risk of biodiversity loss. A similar observation is applicable to the second yeast species $y(t)$. In this case, when the model parameter values are fixed, the simulated growth rate data range from 10.0 and increased monotonically to 38.2492 compared to the range from 10.0 to 32.0987 due to a ten (10) percent variation of the intrinsic growth rates. We have also observed that biodiversity loss is quantified to range from 0 to 16.08 .

In summary, by comparing these two dominant scenarios of biodiversity loss, it is very clear that the first yeast species is almost double more vulnerable to biodiversity loss than the second yeast species. Similar observations are applicable to Table 2 and Table 3. On the basis of this analysis, we have observed that a ninety - eight (98) percent variation of the inter - competition coefficient together has predicted a far lower volume of biodiversity loss as expected which can be tolerated because it is an evidence that this devastating ecological risk will soon be lost at the next level of variation such as hundred and one (101) percentage variation.

\section{CONCLUSION}

We have successfully utilized the technique of ODE 45 numerical scheme to model the possibility of biodiversity loss. These results have been discussed quantitatively. A small variation of the inter - competition coefficient together is dominantly associated with a higher vulnerability to biodiversity loss whereas the inevitability of biodiversity loss which should be expected can be tolerated for a lower decreasing volume of the intrinsic growth rates together. It is therefore necessary to find some sort of mitigation measures that will recover biodiversity loss and sustain biodiversity gain. This idea will be key subject in our next investigation.

\section{REFERENCES}

[1] Atsu, J. U. \& Ekaka-a, E. N. (2017). Modeling the policy implications of biodiversity loss: A case study of the Cross River national park, south -south Nigeria. International Journal of Pure and Applied Science, Cambridge Research and Publications. vol 10 No. 1; pp 30-37.

[2] Atsu, J. U. \& Ekaka-a, E. N. (2017). Quantifying the impact of changing Intrinsic growth rate on the biodiversity of the forest resource biomass: implications for the Cross River State forest resource at the Cross River National Park, South - South, Nigeria: African Scholar Journal of Pure and Applied Science, 7(1); 117 - 130.

[3] De Mazancourt, C., Isbell, F., Larocque, A., Berendse, F., De Luca, E., Grace, J.B et al. (2013). Predicting ecosystem stability from community composition and biodiversity. Ecology Letters, DOI: $10.1111 /$ ele.12088.

[4] Ernest, S.K.M. \& Brown, J.H. (2001). Homeostasis and compensation: the role of species and resources in ecosystem stability. Ecology, 82, 2118-2132.

[5] Fowler, M.S., Laakso, J., Kaitala, V., Ruokolainen, L. \& Ranta, E. (2012).Species dynamics alter community diversity-biomass stability relationships. Ecol. Lett., 15, 1387-1396.

[6] Gonzalez, A. \& Descamps-Julien, B. (2004). Population and community variability in randomly fluctuating environments. Oikos, 106, 105-116.

[7] Grman, E., Lau, J.A., Donald, R., Schoolmaster, J. \& Gross, K.L. (2010). Mechanisms contributing to 
stability in ecosystem function depend on the environmental context. Ecol. Lett., 13, 1400-1410.

[8] Hector, A., Hautier, Y., Saner, P., Wacker, L., Bagchi, R., Joshi, J. et al. (2010). General stabilizing effects of plant diversity on grassland productivity through population asynchrony and overyielding. Ecology, 91, 2213-2220.

[9] Loreau, M.. \& de Mazancourt, C.. (2013). Biodiversity and ecosystem stability: a synthesis of underlying mechanisms. Ecol. Lett., DOI: 10.1111/ele.12073.

[10] MacArthur, R. (1955). Fluctuations of Animal Populations, and a Measure of Community Stability. Ecology, 36, 533-536.

[11] Marquard, E., Weigelt, A., Roscher, C., Gubsch, M., Lipowsky, A. \& Schmid, B. (2009). Positive biodiversity-productivity relationship due to increased plant density. J. Ecol., 97, 696-704.

[12]May, R.M. (1973). Stability and complexity in model ecosystems. 2001, Princeton Landmarks in Biology edn. Princeton University Press, Princeton. McCann, K.S. (2000). The diversity-stability debate. Nature, 405, 228-233.

[13] McNaughton, S.J. (1977). Diversity and stability of ecological communities: a comment on the role of empiricism in ecology. Am. Nat., 111, 515-525.

[14] Mutshinda, C.M., O’Hara, R.B. \& Woiwod, I.P. (2009). What drives community dynamics? Proc. Biol. Sci., 276, 2923-2929.

[15] Proulx, R., Wirth, C., Voigt, W., Weigelt, A., Roscher, C., Attinger, S. et al.(2010). Diversity Promotes Temporal Stability across Levels of Ecosystem Organization in Experimental Grasslands. PLoS ONE, 5, e13382. 